\title{
RESEÑA: LA LACTANCIA MATERNA. POLÍTICA E IDENTIDAD. BEATRIZ GIMENO ${ }^{1}$
}

\author{
Luis León Prieto ${ }^{2}$
}

\section{Beatriz Gimeno, La lactancia materna. Política e identidad. Madrid: Ediciones Cátedra, 2018. ISBN: 978-84-376-3839-3.}

La autora que firma este ensayo, Beatriz Gimeno, es escritora, activista y, actualmente, diputada en la Asamblea de Madrid; además, la motivación de la que parte en la escritura de esta obra le ha venido a través de razones personales, tal y como expone en la introducción a la misma. Gimeno, tras el nacimiento de su hijo en un hospital público, decidió no amamantarle y esto supuso el comienzo de una campaña de presión, por parte del personal sanitario, a favor de la lactancia materna, incluso aunque conllevara un perjuicio físico y psicológico para la madre primeriza. Años más tarde, cuando Gimeno ya se había incorporado al activismo feminista, fue consciente de que, si el cuerpo de las mujeres siempre ha constituido un campo de batalla, el poder de estas para tomar decisiones sobre sus propios cuerpos ha estado muy ligado a la capacidad, también, de controlar de qué manera ejercen su maternidad.

Tras la Segunda Ola feminista, en los años sesenta y setenta del pasado siglo, se cuestionó la propia institución de la maternidad, pero, a partir de los ochenta, se daría una

\footnotetext{
${ }^{1}$ Fecha de recepción: 23/11/2018.

Fecha de aceptación: 25/11/2018.

${ }^{2}$ Doctorando en el programa de Género y Diversidad de la Universidad de Oviedo, Departamento de Filología Inglesa, Francesa y Alemana, Universidad de Oviedo; $\square$ UO248699@uniovi.es.
} 
estrategia reaccionaria en este sentido, en el contexto de un repunte del neoliberalismo político y económico. La maternidad volvería a ser exaltada, aunque esta vez utilizando estrategias que se pretendían feministas y liberadoras para todas las mujeres. En esta obra, la intención de la autora es dilucidar de qué manera tuvo lugar esa evolución, desde un feminismo que cuestiona la maternidad como institución establecida hasta llegar a otro feminismo, desligado del anterior pero con postulados totalmente opuestos, que, a su manera, también considera liberadores.

En el primer capítulo, Gimeno analiza la lactancia a través de una perspectiva histórica, comprobando cómo, en aquellos momentos en los que las mujeres gozaban de mayor libertad, y amamantaban menos, era cuando se producían las reacciones patriarcales a favor de la lactancia. La autora señala cómo el mito del instinto maternal, del amor maternal como se entiende hoy día, en realidad siempre ha coexistido con el abandono y el infanticidio, con la lucha por la supervivencia. Y, al contrario de lo que sucede en la actualidad, eran las mujeres ricas las que se permitían no amamantar, dejando a sus hijos al cuidado de nodrizas, mujeres más pobres que se ocupaban de la lactancia. En la Edad Media, la imagen de la maternidad ideal se correspondía con María, madre de Dios; durante el Renacimiento, la figura de esa buena madre se contrasta con la de la bruja, en los momentos álgidos de su persecución. Fue en el siglo XVIII, con Rousseau, cuando comienza el proceso de exaltación de la madre, que continúa incluso a través de la Primera Ola feminista del XIX. Este siglo también alumbró el surgimiento del citado mito del instinto maternal, basado en comportamientos animales analizados por Darwin, y también el nacimiento de la "maternidad científica", con un discurso médico que comenzó a considerar el biberón un método válido frente a la lactancia, junto a la 
aparición de la pediatría y de otra serie de especialidades destinadas a construir el discurso moderno sobre la gestión de la maternidad.

Esta corriente científica, que no imponía el amamantamiento como ideal, provocó que muchas mujeres abandonaran la lactancia hacia los años cincuenta del pasado siglo. En el segundo capítulo, Gimeno analiza el proceso de reconstrucción de la maternidad que se produjo desde entonces, llegando a alcanzar una hegemonía a partir de los ochenta, como ya se señaló. Entre ambas épocas se sitúan los años sesenta y su Segunda Ola, con el incremento de autonomía que supuso para las mujeres en el control de sus propios cuerpos, un hecho seguido por la pertinente reacción patriarcal a favor de un determinado modelo de maternidad. Con este fin, surgieron teorías como las del apego o el vínculo y, sobre todo, poderosos grupos de presión como La Liga de La Leche, una asociación fundada por madres católicas de Chicago en los años cincuenta, cuyo fin principal era la promoción de la lactancia, pero que, aun valiéndose de ideas provenientes del feminismo, defendía y sigue defendiendo un tipo de maternidad totalmente subordinada al acto de amamantar.

Una de las consecuencias de esa reacción a favor de una determinada clase de maternidad fue el establecimiento de la lactancia como un imperativo moral, motivo que Gimeno aborda en el tercer capítulo. Como declara la autora, este mandato moral no solo indica que la lactancia convierte a la mujer en mejor madre, sino que, además, es una práctica que mejora el mundo. El discurso médico y científico actual ha determinado que, no solo la lactancia materna es mejor, sino que la leche de fórmula puede suponer un riesgo, lo cual pondría a la madre en el compromiso ético de amamantar, sintiéndose culpable si no pudiera hacerlo. Por otra parte, aunque las activistas de la lactancia hablan 
del concepto de "libre elección" a la hora de defender esta actividad, en realidad se trata de una mera retórica, puesto que elegir no amamantar resulta prácticamente imposible, a través de las presiones y del hecho de que la mayoría de información que circula sobre este asunto se muestra a favor de la lactancia materna. Además de la presión para amamantar, las madres contemporáneas se ven inducidas a convertir su lactancia en un proceso de disciplina para el cuerpo, en una especie de empresa en la que lo importante es el éxito, como si se tratara de una actividad deportiva o profesional. Para algunas activistas de la lactancia, se trata de un proyecto con dos únicas salidas: el éxito o el fracaso.

Y este proyecto, así concebido, se muestra en consonancia con el neoliberalismo que impera en la actualidad, tal y como apunta Gimeno en el capítulo cuarto, que dedica al proceso de construcción subjetiva de la identidad "lactivista", que así es como alude al activismo a favor de la lactancia. Dicha identidad es propia de una época no solo neoliberal, sino también marcada por los postulados de la posmodernidad. La etapa posmoderna se caracteriza, entre otros rasgos, por el abandono de las antiguas religiones y creencias, que son sustituidas por ideales laicos, como, por ejemplo, la maternidad. El "lactivismo" al que se refiere Gimeno se constituye en una especie de religión laica, con grupos de apoyo y reuniones en las que, más allá de la promoción concreta de la lactancia, las mujeres pueden experimentar un sentimiento de pertenencia, identitario e, incluso, una sensación de espiritualidad enriquecedora para sus vidas. Por otro lado, esta clase de activismo se ha extendido en la actualidad a través de toda una serie de recursos cibernéticos, como los blogs acerca de la maternidad. Estos no solo significan un elemento de expresión y comunicación entre madres, sino que, además, pueden servir de herramienta para presionar y atacar aquellos discursos discordantes con la postura 
hegemónica sobre la lactancia. Gimeno recoge un caso aparecido en la prensa española, un artículo titulado “¿Madre o vaca?”, que pretendía abrir un debate pero desató una encendida polémica y numerosas voces críticas dentro de este universo de la red.

La dicotomía entre la construcción natural y la construcción científica de la maternidad centra el capítulo quinto. Gimeno recuerda otra dicotomía, que ha estado vigente desde la antigüedad, la que equipara a la mujer con la naturaleza y al hombre con la cultura. Esta línea de pensamiento ha desembocado en mitos como el ya citado del instinto maternal, y ha otorgado un enfoque masculino respecto a la ciencia. El sistema científico, por otra parte, se ha convertido en un dogma que sustituye a la ideología religiosa y refleja el pensamiento dominante que, en este caso, sería aquel favorable a la lactancia. Con el fin de mantener esta posición de hegemonía, la gran mayoría de artículos aparecidos tanto en medios académicos como divulgativos se dedican a promocionar la lactancia, mientras que los textos divergentes de esta línea no suelen encontrar espacios de publicación, o son más difíciles de rastrear. Por otro lado, también desde organismos oficiales y transnacionales, como la OMS o UNICEF, además de algunas influyentes asociaciones de pediatras, se reitera el apoyo a la leche materna. Gimeno destaca cuatro fases en cuanto a políticas de lactancia en los siglos XX y XXI: la lactancia como base a mediados del XX, cuando se considera lo natural pero también se admite el biberón como un imitador, un sustituto útil en ciertos casos; la lactancia como norma a finales del XX, cuando la labor de lobby de las principales asociaciones pro leche materna presionan para poner a las madres en una situación de servidumbre hacia la lactancia; la leche de fórmula como riesgo a principios del XXI, con una estrategia del miedo y culpabilizadora hacia las madres que no recurren a la lactancia, y la lactancia como un asunto de salud pública, 
que constituye incluso una especie de deber patriótico y llega a considerar la leche de fórmula al nivel de una droga peligrosa.

En el sexto y último capítulo, Gimeno alude a cuestiones de raza y clase social referentes a la lactancia. En la actualidad, la mayoría de las mujeres que amamantan son blancas, de clase media y en el marco de una pareja heterosexual. La lactancia se ha convertido en un instrumento al servicio del clasismo y el racismo, especialmente en países como Estados Unidos, donde las madres de clase trabajadora negras y chicanas son menos proclives a la lactancia y, además, conservan importantes redes de apoyo que las ayudan en el cuidado de los bebés. En el caso de las mujeres negras, por otro lado, existe una gran reticencia hacia los intentos de control externo hacia sus cuerpos, debido a la tradición de la esclavitud y a las estrategias de resistencia que se llevaron a cabo frente a las prescripciones médicas de la sociedad esclavista. Por otra parte, pese a la promoción pública de la lactancia, se considera que esta es una actividad que se debe realizar en un espacio privado, según el puritanismo que ha sexualizado la figura del pecho femenino, y, de manera especial, los cuerpos de esas mujeres negras, que históricamente se han enmarcado en procesos de sexualización, incluso animalización. Dentro de estas contradicciones imperantes en la promoción de la lactancia, Gimeno concluye con la consideración de que, en la época actual, el cuerpo humano se ha convertido en un objeto $y$, en este contexto, no solo la lactancia ha llegado a ser un negocio lucrativo, sino que, además, la leche materna ha devenido también en un producto comercial, al margen del propio amamantamiento. La lactancia, pues, ha terminado siendo tanto una herramienta del sistema patriarcal para fortalecer los roles de género y construir una maternidad simbólica, como un mercado boyante para las industrias asociadas a esta actividad. 
En conclusión, podría decirse que con esta obra, en la que confluye su trayectoria tanto de escritora como de activista, Gimeno demuestra, a través de una tesis sólida y documentada, que no es una autora que evite la controversia. De hecho, posee una vasta experiencia en la exposición de temas polémicos para el feminismo, como es el de la prostitución; con La lactancia materna, Gimeno busca contrarrestar ese discurso oficial ya aludido, que silencia las voces contrarias a través de una presión que la propia autora ya ha podido sentir en las redes sociales, desde que esta obra fue publicada. Cabe esperar que la aportación que propone en este texto pueda propiciar un debate más sereno sobre el asunto que el que domina en la actualidad. 